\title{
Through-life Engineering Services
}

\section{Rajkumar Roy, Andy Shaw, John Ahmet Erkoyuncu and Louis Redding}

EPSRC Centre for Innovative Manufacturing in Through-life Engineering Services Manufacturing and Materials Department Cranfield University

Cranfield, Bedford, MK43 0AL, UK

Email: r.roy@cranfield.ac.uk

URL: www.through-life-engineering-services.org

\subsection{Introduction}

High value manufacturing companies are increasingly offering through-life support for their products and guaranteeing the performance over the contracted period. Within the aerospace and defence sectors, over $55 \%$ of the revenue is coming from these Through-life Engineering Services (TES) today and it is growing. Other sectors, such as railways, wind energy and automotive have also recognized the potential and are striving to grow their TES business. In addition, the UK is one of the major countries offering maintenance-repair-overhaul service in the world, with over $17 \%$ market share in the sector. With the increasing popularity of performance based contracts (e.g. 'Power by the Hour' contracts from Rolls-Royce) or availability contracts or industrial product-service systems (IPS ${ }^{2}$ ) [1] for long life and high value equipments, manufacturers are looking to increase the life of components, reduce the maintenance costs and to maximise their net profit. Through-life Engineering Services are the technical services that are necessary to guarantee the required and predictable performance of a complex engineering system throughout its expected operational life with the optimum whole life cost. Examples of the complex engineering systems include aircraft engines and wind turbines to railway carriages and military equipments.

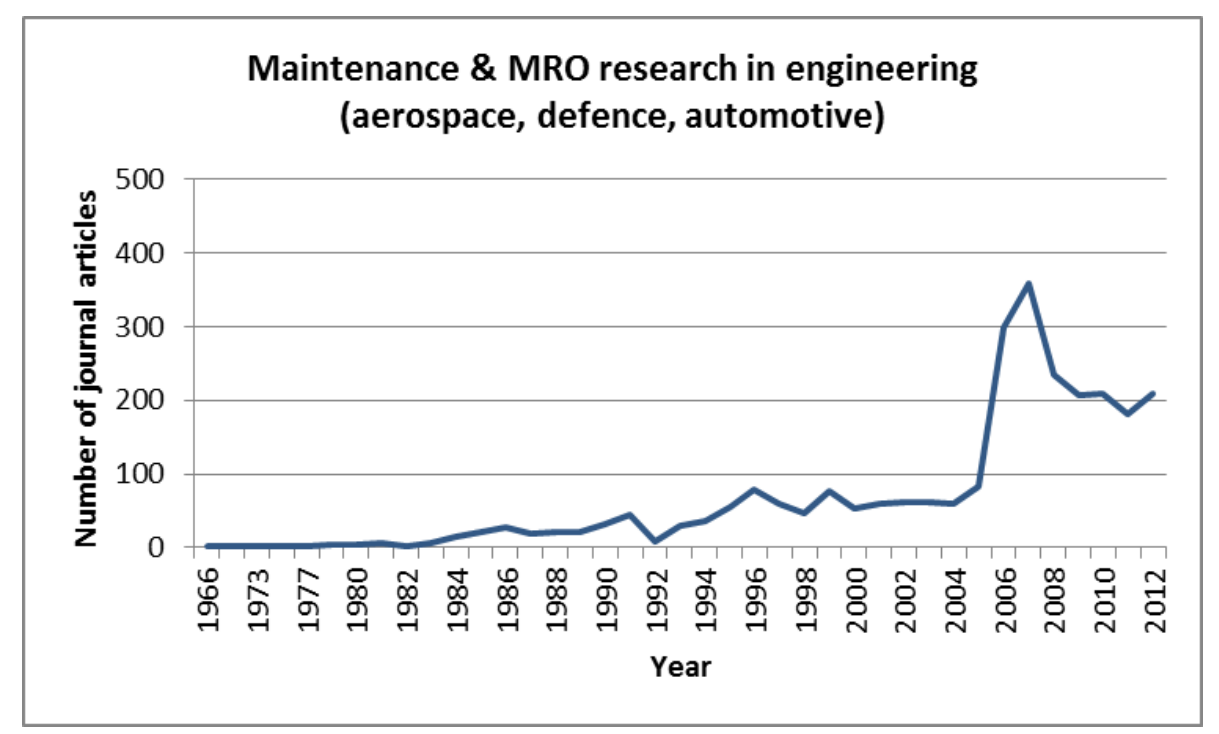

Figure 1. Number of research papers in maintenance and MRO [2]

TES research is focusing on developing technology and engineering solutions to address the new support requirements for performance based contracts. Maintenance is the major engineering service in performance based contracts [2]. Maintenance involves a combination of technical, administrative and managerial actions during the life cycle of an item with the 
aim of retaining it in, or restoring it to, a state in which it can perform the required function

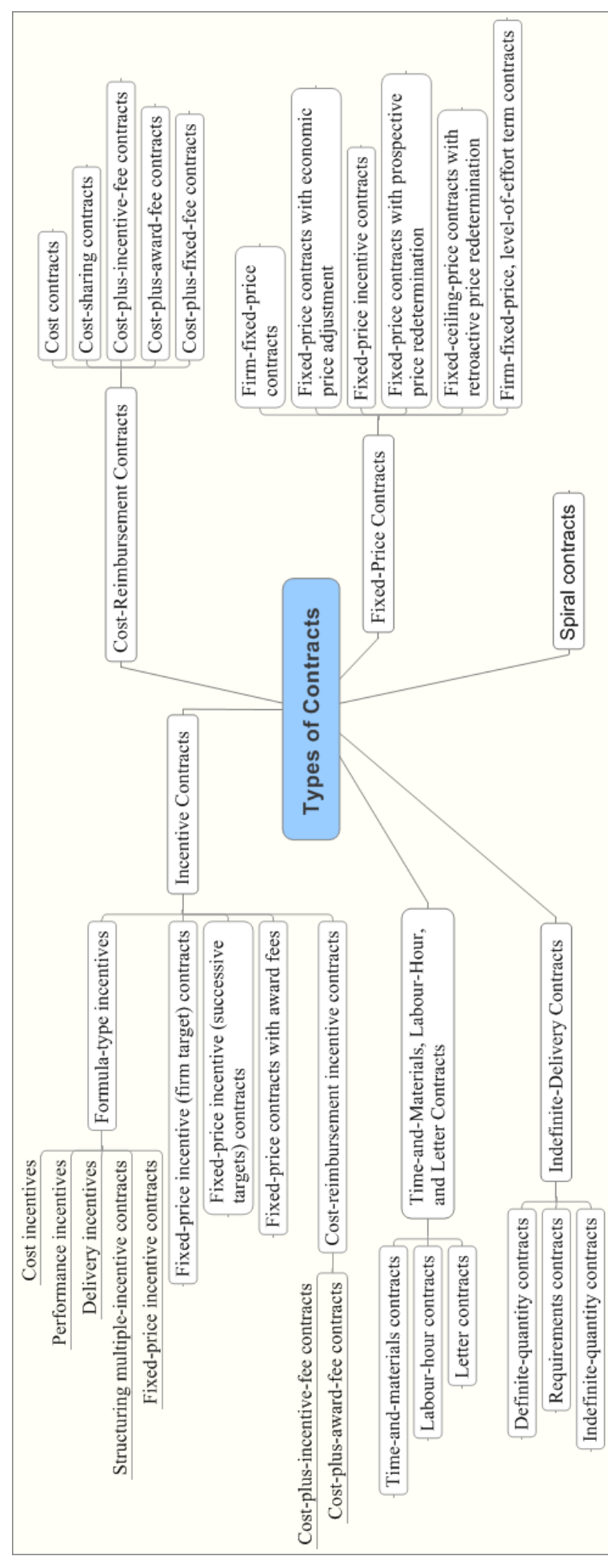

[3]. Also, maintenance, repair, and overhaul (MRO) involves resolving any sort of mechanical, system, electrical or electronic device issues when they fail to fulfil their design function through breakdown. Whilst the customer is typically acknowledging the large cost burden experienced from maintenance, innovative forms of contracting are increasingly emerging that put further pressure on the solution provider to extend the product life cycle through services and so reduce the overall cost [4,5]. Figure 1 shows the number of papers published in the MRO area and the growth in research interest over last few years. Recognising the national need and the growing industrial interest, the EPSRC in the UK has already funded a national Centre for Innovative Manufacturing in TES along with a number of key industry partners. This paper outlines the key areas of research for the EPSRC Centre.

\subsection{Industrial Product Service System contracts and change in ownership}

The types of contracts used for IPS ${ }^{2}$ defines the commercial environment and outcomes expected from the service. The contracts are primarily of three categories: 1) maintenance, repair, overhaul, service and support; 2) availability, performance; and 3) capability, function and result [3]. The types of contracts used in IPS ${ }^{2}$ are explained in Figure 2. Across the research community and industry these contracts are used based on the type of IPS $^{2}$ business model and are known by various names based on the business concept. One of the objectives of these contracts is to manage the risks associated with these long-term contracts. The risk management includes identifying the best approach to share the

Figure 2: Types of contracts used in IPS ${ }^{2}$ [3]

technological, business and commercial risks across the service network (i.e. the supply chain for TES). The change in ownership of some of the major risks to the manufacturer (often with a fixed price) and its service network over the whole life of an equipment encourages the manufacturer to design the equipment with longer life components, reduce maintenance costs and improve availability. The aim here is to achieve an optimum whole life cost for the complex engineering system. This risk sharing is a major motivation for the TES research. 


\section{Types of Through-life Engineering Services}

It is observed that the in-service phase of a product life cycle creates the largest amount of cost [2]. Maintenance, which is a driver of in-service costs, to a large extent cannot be avoided due to a number of reasons such as consumables, wear, plug and play technology upgrades, and standardization of interfaces. As a result the customer has become increasingly interested in minimizing the cost of whole life cycle ownership of assets. Strategies have typically moved towards reduction of maintenance (e.g. schemes to avoid failure - design for zero failures), and higher predictability (e.g. visualize future wear) that drives availability. Based on the existing literature and industry requirements, Figure 3 shows different types of TES that are necessary to support performance based contracts [3].

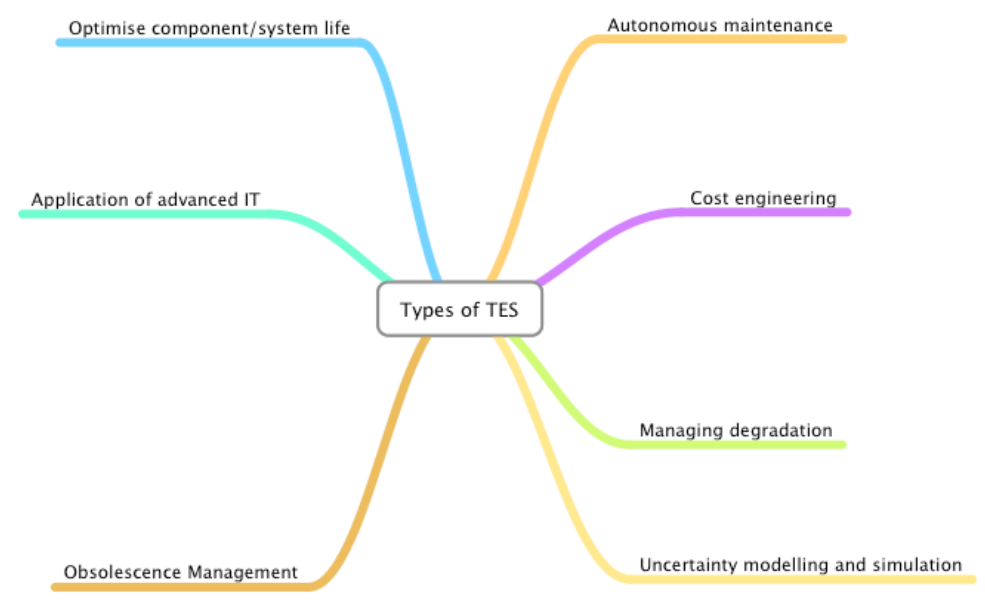

Figure 3: Types of Through-life Engineering Services

\subsection{Application of advanced IT}

The main technologies that assist the application of e-maintenance include the internet, wireless devices, smart tags, micro-size MEMS sensors especially designed for maintenance purposes and low-cost online lubrication analysis sensors [6]. Also, information-processing tools enable continuous data flow through a distributed and collaborative web platform system at the higher end of the processing hierarchy. These assist in re-designing maintenance strategies in a cost effective and environmentally friendly manner based on condition monitoring information and prognostics. Such approaches have been comprehensively reported in the literature, however Redding et al., [7] highlight that the application of such technologies has in comparison been below expectations. However, it is expressed that there is a large desire to adopt such technologies.

\subsection{Optimise component/system life}

The maintenance strategy needs to facilitate the optimization of the life cycle of the equipment. For this purpose TES will need to concentrate on a) developing suitable simulation approaches; b) schemes that facilitate adaptability; c) modular maintenance and d) disposal decision making [6]. A common feature of the life cycle is the need to modify the equipment because of changes in capability requirements, affordability issues, or technological advances for example. During the life cycle of maintenance, with up to date information about the equipment health, suitable simulation approaches need to be adopted in order to develop trend analysis and to predict reliable life expectations. Modular maintenance refers to a procedure that allows replacement of major assemblies, called modules, with a 
minimum amount of expenditure and time. Furthermore, the removed modules follow a cycle by being returned to the repair facility, bench test, repair, and inserted back in to the equipment [8]. However, designing this procedure is challenging because one has to consider the sub-modular cost structures that capture the dependencies between various components and modules in the system. It is also important to design suitable redundancy mechanisms and appropriate schemes to resolve maintenance issues such as obsolescence.

\subsection{Managing Degradation}

Degradation refers to the process of deterioration of characteristics of an object with time; gradual decline in quality; and/or breakdown of matter due to the impact of external forces in conformity with the laws of nature and time. The degradation issue could be categorized in to component and system level. At the component level the degradation mechanisms are wear, crack formation and growth, corrosion etc. At the system level the degradation can manifest as no fault found (NFF). NFF refers to system or component that has been returned to the manufacturer or distributor for warranty replacement or service repair, but operates properly when tested in laboratory environment. Given the variety and complexity of mechanisms, there is a need to understand their drivers and ways to mitigate their implications. Figure 4 shows degradation management at the system and component levels.
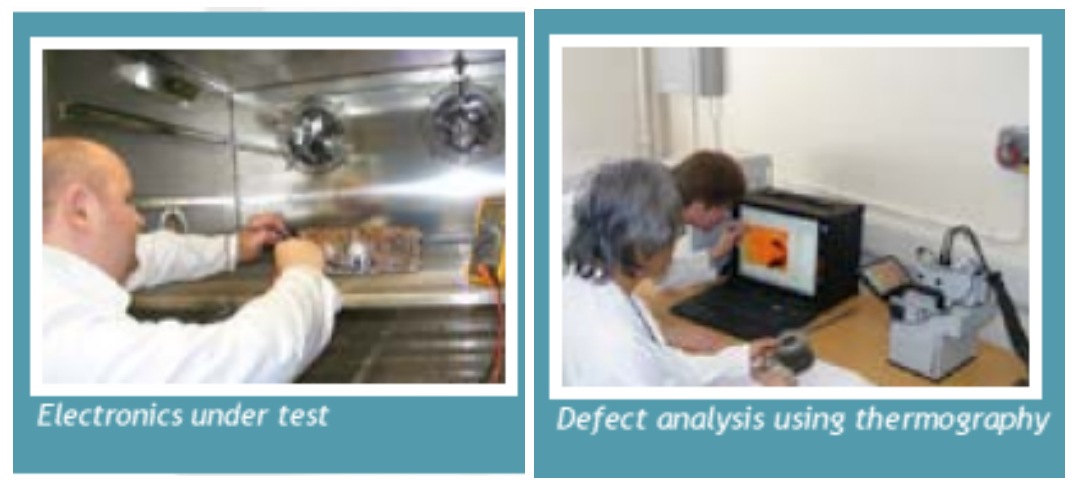

Figure 4: Technologies for the system and component level degradation reduction.

\subsection{Autonomous Maintenance}

Autonomous maintenance means developing capability within a high value system to maintain itself and also developing maintenance systems that collaboratively provide autonomous capability to perform maintenance on a high value system with minimum human intervention. This improves robustness of a system and influences the ability to meet performance and cost targets. Among autonomous maintenance approaches self-healing is attracting much attention. Self-healing systems aim to mitigate, detect and recover from failures [9]. The initial step involves defining an appropriate architecture that specifies components, their relationships within a system coupled with topology (with number and placement of components in a system). This architecture helps to mitigate the effects of failures by providing guidance with increasing system redundancy. Subsequently, failure detection techniques are applied and involve monitoring component health and uncertainty analysis in order to realize the remaining life in a reliable manner.

\subsection{Obsolescence Management}

A component becomes obsolete when it is no longer available from stock of its own spares, procurable or produced by its manufacturer or suppliers [10]. With performance-based contracts the responsibility to manage the obsolescence is shifting towards the manufacturer and its service network. Manufacturers are required to better understand the causes of 
obsolescence, how to resolve them, how to cost them and how to manage them across the service network. TES will include the service network obsolescence management capability assessment, cost estimation and design for obsolescence processes.

\subsection{Cost Engineering}

Performance-based service contracts use performance and whole life cost models to specify the desired materials and resources quality and measure the acceptability of the as-constructed offering. There is very limited literature related to modelling costs in such contracts. Cost modelling for such contracts is different from that in asset management contracts as the objective of cost modelling for such contracts is to determine how much funding is required to meet the target conditions as opposed to how much can be achieved with available funding in traditional asset management contracts [11]. Moreover, input variables in determining service life are stochastic; modelling costs of performance-based service is a complex process and requires greater understanding of equipment usage.

\subsection{Uncertainty Modelling and Simulation}

Uncertainty modelling needs to be studied at two levels: technological uncertainties and business uncertainties. The technological uncertainties will involve uncertainty modelling for the technologies developed as part of TES and improve the design based on the uncertainty information. Performance-based contracts involve additional uncertainties due to their long term contracting nature and due to the strong service content of the contract. There are three major traits of the uncertainties: emergent traits that make uncertainties apparent specifically within the context; metamorphic traits that result in changes to uncertainties over time; and conformance traits that cause uncertainties to be experienced commonly from project to project [5]. There is a need to systematically derive the level of uncertainty and its impact on a contract through dynamic simulation.

\subsection{Concluding Remarks}

Performance-based contracting has become popular in many industry sectors. TES provides the necessary support for the contracts to achieve the required performance with optimum whole life cost. There are seven major types of TES that are necessary to improve the contract delivery efficiency and optimise the cost. The technology developed through TES will address the maintenance requirements at the component and system levels.

\section{Acknowledgements}

The authors acknowledge the EPSRC and industry partner funding to the EPSRC Centre for Innovative Manufacturing in Through-life Engineering Services. The EPSRC Centre is hosted by Cranfield University and Durham University. Additionally, the support of colleagues in the Manufacturing and Materials Department at Cranfield University is acknowledged.

\section{References}

[1] Meier, H., Roy, R., Seliger, G.: Industrial Product-Service Systems - IPS ${ }^{2}$. CIRP Annals Manuf. Tech, 59(2), 607-627 (2010).

[2] Roy, R., Erkoyuncu, J. A., Shaw, A.: The future of maintenance for industrial productservice systems. Keynote Paper. 14-15 March, Proceedings of the CIRP IPS ${ }^{2}$ Conference, Bochum, 1-15 (2013). 
[3] Roy, R., and Cheruvu, K.: A competitive framework for Industrial Product Service Systems, Int. J. of Internet Manuf. and Serv., Special Issue on Product Service Solutions in Life-Cycle Activities, 2(1), 4-29 (2009).

[4] Ng, I., Yip, N.: Identifying risk and its impact on contracting through a benefit based model framework in business contracting: Case of the Defence industry, Proceedings of the 1st CIRP IPS2 Conference, Cranfield, pp. 207-215 (2009).

[5] Erkoyuncu, J. A.: Cost Uncertainty Management and Modelling for Industrial ProductService Systems, PhD Thesis, Cranfield University (2011).

[6] Shaw, A., Roy, R.: Think Tank Report, EPSRC Centre for Innovative Manufacturing in Through-life Engineering Services, Cranfield University, UK (2012).

[7] Redding, L.E., Tiwari, A., Roy, R.: Identifying the the challenges in Through-life Engineering Services, Proceedings of the $1^{\text {st }}$ International Conference on Through-Life Engineering Services, Shrivenham, Cranfield University, 159-165 (2012).

[8] Kececioglu, D. Maintainability, Availability, \& Operational Readiness Engineering, Prentice Hall PTR, Upper Saddle River, NJ. (1995).

[9] McWilliam, R., Purvis, A., Jones, D., Schiefer, P., Frei, R., Tiwari, A., Zhu, M.: Selfrepairing electronic logic units based on convergent cullar automata, Proceedings of the 1st International Conference on Through-Life Engineering Services, Shrivenham, Cranfield University, 353-360 (2012).

[10] Romero Rojo, F J, Roy, R, Shehab, E, Cheruvu, K, and Mason, P,: A cost estimating framework for electronic, electrical and electromechanical (EEE) components obsolescence within the use-oriented product-service systems contracts, Inst. of Mech. Eng. Part B J. of Eng. Manuf., 226, 154-164 (2011).

[11] Datta, P.P., and Roy, R.: Cost modelling techniques for availability type service support contracts: A literature review and empirical study, CIRP J. of Manuf. Sci. and Tech. 3(2), 142-157 (2010). 